Alma Mater Studiorum - Università di Bologna DEPARTMENT OF ECONOMICS

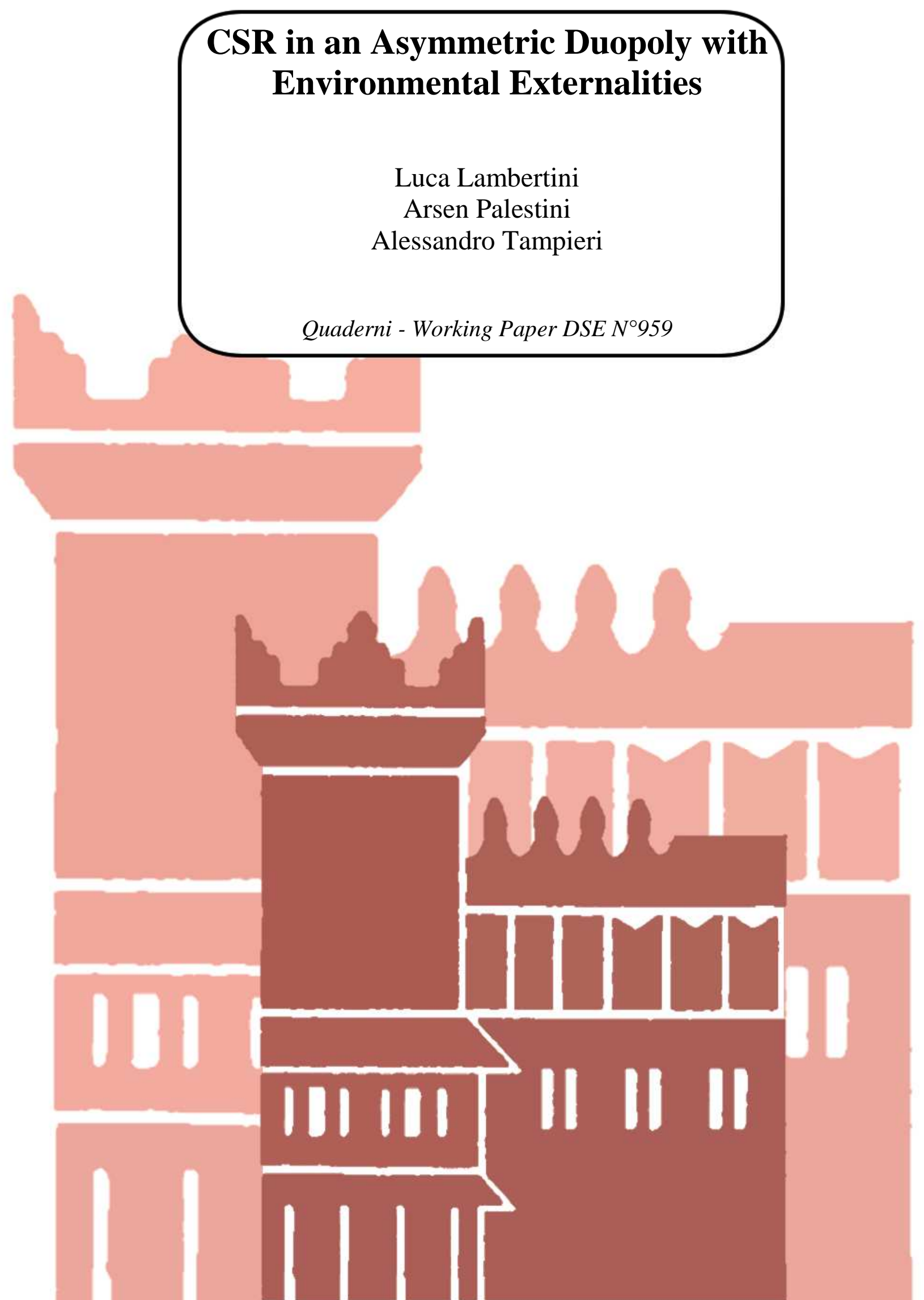




\title{
CSR in an Asymmetric Duopoly with Environmental Externalities*
}

\author{
Luca Lambertini \\ Department of Economics, University of Bologna \\ ENCORE, University of Amsterdam \\ Luca.Lambertini@unibo.it
}

Arsen Palestini

MEMOTEF, Sapienza University of Rome

Arsen.Palestini@uniroma1.it

Alessandro Tampieri

Alessandro Tampieri

Faculty of Law, Economics and Finance, Université du Luxembourg

tamp79@gmail.com

25th August 2014

\begin{abstract}
We investigate a linear state differential game describing an asymmetric Cournot duopoly with capacity accumulation à la Ramsey and a negative environmental externality (pollution), in which one of the firms has adopted corporate social responsibility (CSR) in its statute, and therefore includes consumer surplus and the environmental effects of production in its objective function. If the market is sufficiently large, the CSR firm sells more, accumulates more capital and earns higher profits than its profit-seeking rival.
\end{abstract}

JEL codes: C73, H23, L13, O31.

Keywords: Capital accumulation, asymmetric duopoly, dynamic games.

*We would like to thank Dean Carlson, Fabio Lamantia and Georges Zaccour and the seminar audience at the ISDG conference 2012 for valuable comments. The usual disclaimer applies. 


\section{Introduction}

Firms embracing a Corporate Social Responsibility (CSR, henceforth) regime take into account not only the shareholder interests (profit), but also how the firm decisions affect the agents dealing with the firm (stakeholders), such as employees, business partners, consumers and environment. The presence of CSR is viewed by its supporters as a self-regulating tool, as it leads firms to internalise the environmental effects caused by production. On the one hand, a firm may rationally anticipate that environmental regulation will become stricter and therefore her anticipated concerns may create to her a competitive advantage. Secondly, corporate managers have environmental preferences or shareholders have and ask managers to follow a strategy consistent with them. Finally, green consumers penalise firms without environmental concerns, raising pollution costs and therefore acting as a sort of Pigouvian tax mechanism. Conversely, who is against CSR argues that a corporation's purpose is to maximize returns to its shareholders, and that since only people can have social responsibilities, corporations are only responsible to their shareholders and not to society as a whole (Friedman, 1962 and 1970).

The interest on the analysis of CSR is quite recent in the economic literature. ${ }^{1}$ On the theoretical side, CSR firms have been analysed from several perspectives. ${ }^{2}$ One strand identifies CSR with creation of public goods or curtailment of public bads (Bagnoli and Watts, 2003, Kotchen, 2006, Besley and Ghatak, 2010), generally showing that there is a close parallel between CSR so defined and the results obtained by the models of private provision of public goods. Other contributes study the desirability of CSR (Baron, 2001), the role of CSR in selecting motivated agents (Brekke and Nyborg, 2005) or the firm competition in the presence of "green" consumers (Arora and Gangopadhyay, 1995 and Garcia-Gallego and Georgantzís, 2009) or social pressure (Baron, 2009). Finally, Manasakis et al. (2007), Alves and SantosPinto (2008) and Lambertini and Tampieri (2010) examine the strategic effects between CSR and profit-maximising firms.

All these theoretical approaches to the analysis of the CSR display a specific static setting. To the best of our knowledge, little has been said about dynamic analysis in the presence of CSR. Becchetti and Solferino (2005) account for firm interactions in a dynamic setting. They compute the open-loop Nash equilibrium between duopolists that are differentiated according to their CSR position along the Hotelling line. Wirl et al. (2013) analyse a dynamic framework of a firm's CSR activities to analyze how a firm should pursue its CSR activities over time, while taking into account that the relative position with respect to its competitors is an important determinant for its reputation, and thus long run profit. Even though these contributions highlight the role of strategic interaction in CSR activities over time, the role of a CSR firm in affecting and capital accumulation is still to investigate. Our aim with the present analysis is to fill this gap.

In this paper we investigate a state-linear differential game describing an asymmetric

\footnotetext{
${ }^{1}$ For an overview, see Benabou and Tirole (2010).

${ }^{2}$ On the empirical side, the relatively large research on CSR has mainly focussed on financial performance, finding a mixed support to the view that altruistic behaviour is detrimental to profits. See Murray and Volgel (1997), Mohr et al., (2001), Becchetti and Ciciretti (2009), Fernández-Kranz and Santaló (2010) and FisherVanden and Thorburn (2011), inter alia. For a comparative analysis among studies on CSR and firms' economic performance, see Margolis et al. (2007).
} 
Cournot duopoly with capacity accumulation à la Ramsey and a negative environmental externality (pollution). The analysis is based on the framework of optimal capital accumulation in differential games (Kamien and Schwartz, 1979, Reinganum, 1980, Fershtman and Muller, 1984, and Cellini and Lambertini, 1998, inter alia). Competition is asymmetric since one firm has standard, profit-maximising objectives, whereas its competitor adopts CSR principles in its statute. We define as "CSR" a firm that takes into account not only its profits but also internalises its own share of the externality and is sensitive to consumers' welfare. Thus the CSR firm includes a share of consumer surplus and the environmental effects of production in its objective function (Kopel and Brand, 2012, Lambertini and Tampieri 2010, 2012).

It is noteworthy to compare our framework with the analysis carried out by Wirl et al. (2013). In their setup:

- Each firm may undertake some "CSR activities". Conversely, we consider a interaction between a "profit-maximising" (which cannot engage in CSR activities whatsoever) and a "CSR" firm.

- CSR activities result in a specific benefit that a firm obtains from CSR. In our analysis a firm engaging in CSR is modelled in a similar way as a public firm: takes into account other aspects of social welfare such as pollution and (a share of) consumer surplus.

- Firms with similar technology will endeavour in CSR in the same level, resulting in a symmetric interaction. Conversely, the interaction between a profit-maximising and a CSR firm leads to an asymmetric equilibrium.

- The environmental effect of production in terms of pollution is not explicitly taken into account.

- In particular, the analysis of Wirl et al. (2013) is interested on the dynamic of engaging in CSR activities over time. In the present paper we highlight the evolution of capital accumulation and pollution.

The results show that the presence of a CSR firm forces the competitor to consider social concerns, namely, pollution and consumer surplus, in its production decisions. In particular, the environmental concern restrains the production of a CSR firm, while the concern about social surplus expands it. The second effect more than offsets the first one in a large market, because the positive price effect going along with an output expansion is sufficiently large to outweigh the negative effect associated with pollution. As a consequence, with a sufficiently large market, the CSR firm makes higher profits than its profit-seeking firm, and accumulates more capital. For medium-size markets, the CSR firm earns more profits but accumulates less capital than the competitor. Finally in small markets, the profit-maximising firm earns more and accumulates more capital. The paper considers next the technical conditions under which the steady state equilibrium exists and it is stable.

This paper aims to contribute both on the literature on CSR and on technical aspects of differential games. First, we propose an explanation on why a firm decides to commit to CSR principles. In our interpretation, a firm may commit to CSR strategically as this can 
be profitable against standard profit maximisation. This occurs as the strategic interaction of a CSR firm with profit-maximising competitors may lead to higher profits for the former. On the technical side, the dynamic optimisation problem is non-standard, this due to two factors of asymmetry. On the one hand, asymmetry emerges since the firms competing in the duopoly feature different objectives. Second, asymmetry also affects the number of strategic variables at hand. Indeed, while the profit-seeking firm chooses its equilibrium quantities only, the CSR firm also competes by investing in R\&D with the aim of abate polluting emission. The difference is caused by the fact that the profit-seeking firm does not internalise pollution, whereas investing in "green" R\&D helps the CSR firm to abate its own cost. In this way, R\&D investment acts as a self-regulating tool.

The remainder of the paper is organised as follows. Section 2 presents the model, Section 3 shows the steady state equilibrium. Section 4 investigates the conditions under which the equilibrium is stable. Section 5 concludes. The relevant proofs are collected in the Appendix.

\section{The model}

Consider an industry where two firms, 1 and 2, compete in quantities. The game unravels over continuous time $t \in[0, \infty)$. Firms share the same time preferences measured by the discount rate $\rho>0$. At any $t$, firms sell a homogeneous good whose demand function is $p(t)=a-q_{1}(t)-q_{2}(t), a>0$; marginal production cost $c \in(0, a)$ is constant and symmetric across firms. Each firm uses a production function $y_{i}(t)=A k_{i}(t)$, and accumulates productive capacity $k_{i}(t)$ to supply its good, with

$$
\dot{k}_{i}=A k_{i}(t)-q_{i}(t)-\delta k_{i}(t)
$$

as in Ramsey (1928), i.e., capacity accumulates via unsold output; $\delta>0$ is the decay rate of capital. Firm 1 is a CSR agent, while Firm 2 is a pure profit-seeking unit. Additionally, Firm 1 also activates R\&D efforts $x_{1}(t)$ to reduce polluting emissions $S(t)$, whose evolution follows the state dynamics

$$
\dot{S}=\mu\left(q_{1}(t)+q_{2}(t)\right)-\eta S(t)-\nu x_{1}(t)
$$

where $\mu, \eta$ and $\nu$ are positive constants. The instantaneous $\mathrm{R} \& \mathrm{D}$ cost is quadratic in the effort, so that at any $t$ the CSR firm's profit function is

$$
\pi_{1}(t)=[p(t)-c] q_{1}(t)-z x_{1}^{2}(t)
$$

with $z>0$.

CSR companies integrate social and environmental concerns in their business operations. Within the firm, socially responsible behaviours mainly involve employees and relate to issues such as investing in human capital, health and safety, and managing change, while environmentally responsible behaviours relate to the management of natural resources used in the production. Out of the company, CSR behaviours involve a wide range of stakeholders, such as business partners and suppliers, customers, public authorities and local communities. 
Hence we assume a specific CSR objective structure (Lambertini and Tampieri, 2010 and 2012): for the environmental concern, we suppose that the CSR firm internalises its own share of pollution. This assumption follows by the fact that a firm can influence directly only its own production system, and nothing can be done directly to influence the competitors' behaviour. It seems natural to interpret all the other social concerns as a share of consumer surplus (Kopel and Brand, 2012). Thus the objective attributed to the CSR firm is

$$
\Omega_{1}(t)=\pi_{1}(t)-b S(t)+\gamma C S(t)
$$

with $b \in[0,1]$ representing the CSR sensitivity to pollution, $C S(t)=\left(q_{1}(t)+q_{2}(t)\right)^{2} / 2$ being instantaneous consumer surplus and $\gamma \in[0,1]$ being the CSR sensitivity to it. The CSR firm's maximisation problem is:

$$
\max _{q_{1}(t) \geq 0, x_{1}(t) \geq 0} J_{1}=\int_{0}^{\infty} e^{-\rho t}\left[\left(a-q_{1}(t)-q_{2}(t)-c\right) q_{1}(t)-z x_{1}^{2}(t)-b S(t)+\gamma \frac{\left(q_{1}(t)+q_{2}(t)\right)^{2}}{2}\right] d t .
$$

On the other hand, firm 2 aims at maximising $\pi_{2}(t)=[p(t)-c] q_{2}(t)$, thus its maximisation scheme is

$$
\max _{q_{2}(t) \geq 0} J_{2}=\int_{0}^{\infty} e^{-\rho t}\left[\left(a-q_{1}(t)-q_{2}(t)-c\right) q_{2}(t)\right] d t .
$$

Note that firm 2's R\&D cost is not taken into account because a profit-seeking firm does not internalise the pollution effect, then an investment to reduce pollution would be useless and costly. This leads to a non-standard dynamic optimisation problem where asymmetry also affects the number of strategic variables at hand (firm 1 has 2 control variables, firm 2 has only one control variable).

Finally, the instantaneous social welfare is

$$
S W(t)=\pi_{1}(t)+\pi_{2}(t)+C S(t)-S(t) .
$$

\section{$3 \quad$ Steady state analysis}

For convenience throughout the results we denote the market size as $m=a-c$. We are going to investigate open-loop information structure of the model by relying on Pontryagin's Maximum Principle. The firms' Hamiltonians are (omitting the time argument for brevity):

$$
\begin{aligned}
& \mathcal{H}_{1}\left(q_{1}, q_{2}, x_{1}, k_{1}, k_{2}, S, \lambda_{11}, \lambda_{12}\right)=e^{-\rho t}\left(\Omega_{1}+\lambda_{11} \dot{k}_{1}+\lambda_{12} \dot{S}\right) \\
& \mathcal{H}_{2}\left(q_{1}, q_{2}, x_{1}, k_{1}, k_{2}, S, \lambda_{21}, \lambda_{22}\right)=e^{-\rho t}\left(\pi_{2}+\lambda_{21} \dot{k}_{2}+\lambda_{22} \dot{S}\right)
\end{aligned}
$$

where $\lambda_{i j}$ is the costate variable attached by player $i$ to state $j$ for $i, j=1,2$. As it appears from (5), the game is a linear state one, and therefore its open-loop Nash solution is strongly 
time consistent (or equivalently, subgame perfect). ${ }^{3}$

The necessary conditions for maximisation are

$$
\begin{gathered}
\frac{\partial \mathcal{H}_{1}}{\partial q_{1}}=m-q_{1}(2-\gamma)-q_{2}(1-\gamma)-\lambda_{11}+\lambda_{12} \mu=0, \\
\frac{\partial \mathcal{H}_{1}}{\partial x_{1}}=-2 z x_{1}-\nu \lambda_{12}=0
\end{gathered}
$$

as far as the CSR firm is concerned, and

$$
\frac{\partial \mathcal{H}_{2}}{\partial q_{2}}=m-q_{1}-2 q_{2}-\lambda_{21}+\lambda_{22} \mu=0 .
$$

is the first order condition for the profit-maximising firm.

The system of costate equations reads as

$$
\left\{\begin{array}{c}
\dot{\lambda}_{11}=(\rho+\delta-A) \lambda_{11} \\
\dot{\lambda}_{12}=(\rho+\eta) \lambda_{12}+b \\
\dot{\lambda}_{21}=(\rho+\delta-A) \lambda_{21} \\
\dot{\lambda}_{22}=(\rho+\eta) \lambda_{22}
\end{array}\right.
$$

The shadow prices of productive capacities are

$$
\lambda_{11}^{*}(t)=\lambda_{11}(0) e^{(\rho+\delta-A) t}, \quad \lambda_{21}^{*}(t)=\lambda_{21}(0) e^{(\rho+\delta-A) t},
$$

whereas the shadow prices of pollution are

$$
\lambda_{12}^{*}(t)=\frac{\left[(\rho+\eta) \lambda_{12}(0)+b\right] e^{(\rho+\eta) t}-b}{\rho+\eta}, \quad \lambda_{22}^{*}(t)=\lambda_{22}(0) e^{(\rho+\eta) t} .
$$

Note that the related transversality conditions may hold under different circumstances: either if $\lambda_{11}^{*}(t), \lambda_{21}^{*}(t), \lambda_{22}^{*}(t)$ are identically zero or when the relations

$$
\lim _{t \longrightarrow+\infty} e^{-\rho t} \lambda_{i 1}^{*}(t) k_{i}^{*}(t)=0, \quad \quad \lim _{t \longrightarrow+\infty} e^{-\rho t} \lambda_{i 2}^{*}(t) S^{*}(t)=0,
$$

hold. If the profit-seeking firm does not take into account the accumulation of the pollution stock from the beginning of the game, it is intuitive to consider that such costate is identically zero, i.e., $\lambda_{22}^{*}(0)=0$, which also satisfies the related transversality condition. Hence, we can eliminate such costate from the dynamic structure, and remain with 3 costate variables only. A complete discussion on the transversality conditions will be provided in Section 4, when calculating the optimal state trajectories and characterizing the dynamic structure of the equilibrium of the model.

Plugging such optimal state variables into (8), solving (6), (7) and (8) for the costate

\footnotetext{
${ }^{3}$ For an exhaustive overview of linear state games and the strong time consistency property of open-loop strategies, see Mehlmann (1988), Dockner et al. (2000) and Cellini et al. (2005), inter alia.
} 
variables and differentiating with respect to time yields:

$$
\begin{gathered}
\dot{q}_{1}=\frac{\frac{4 z \mu}{v}[A+\eta-\delta] x_{1}(t)-2 b \mu-(A-\delta-\rho)\left[q_{1}(t)(3-\gamma)-(1+\gamma) m\right]}{3-\gamma}, \\
\dot{q}_{2}=\frac{(\delta+\rho-A)\left[(\gamma-1) m+q_{2}(t)(3-\gamma)\right]+\frac{2 z \mu}{v}[A+\eta-\delta] x_{1}(t)-b \mu}{-\gamma+3}, \\
\dot{x}_{1}=(\eta+\rho) x_{1}(t)-\frac{b \nu}{2 z} .
\end{gathered}
$$

Such expressions are helpful to determine the unique steady state of the system (uniqueness is ensured by the linearity of the system, whereas the conditions for its existence and stability are outlined in Section 4), together with (1), for $i=1,2$, and (2). Calling $P^{s s}=$ $\left(q_{1}^{s s}, q_{2}^{s s}, x_{1}^{s s}, k_{1}^{s s}, k_{2}^{s s}, S^{s s}\right)$ the steady state in the control-space set, we will obtain the following coordinates:

$$
\begin{gathered}
q_{1}^{s s}=\frac{1}{3-\gamma}\left[(\gamma+1) m-\frac{2 \mu b}{\rho+\eta}\right] ; \\
q_{2}^{s s}=\frac{1}{3-\gamma}\left[(1-\gamma) m+\frac{\mu b}{\rho+\eta}\right] ; \\
x_{1}^{s s}=\frac{b \nu}{2(\rho+\eta) z} ; \\
k_{1}^{s s}=\frac{1}{(3-\gamma)(A-\delta)}\left[(\gamma+1) m-\frac{2 \mu b}{\rho+\eta}\right] ; \\
k_{2}^{s s}=\frac{1}{(3-\gamma)(A-\delta)}\left[(1-\gamma) m+\frac{\mu b}{\rho+\eta}\right] ; \\
S^{s s}=\frac{4 \mu z m(\rho+\eta)+b(\gamma-3) \nu^{2}-2 b \mu^{2} z}{2(3-\gamma) \eta z(\rho+\eta)} .
\end{gathered}
$$

Note that, provided $\gamma \in[0,1]$ and $A>\delta$ (see Propositions 4 and 5), we can enunciate the suitable conditions on parameters to ensure feasibility of $P^{s s}$.

Proposition 1. If

$$
m>\max \left\{\frac{2 \mu b}{(\gamma+1)(\rho+\eta)}, \frac{b\left[(3-\gamma) \nu^{2}+2 \mu^{2} z\right]}{4 z \mu(\rho+\eta)}\right\}
$$

then all the coordinates of $P^{s s}$ are positive, hence it is feasible.

Proof. See Appendix.

Relying on the expression of $P^{s s}$, a few considerations can be summarised as follows.

Proposition 2. In steady state, the adoption of a CSR mandate by a firm induces the rival

(i) to account for the effect of production on the environment and consumer surplus.

(ii) to increase its output with the size of environmental impact of production.

(iii) to reduce its output with the share of consumer surplus. 
Proposition 2 deserves few comments. The fact that the CSR firm takes into account pollution and consumer surplus in its maximisation problem has two effects on the behaviour of its profit-maximising competitor. On the one hand, the sensitivity to pollution induces the CSR firm to restrain its output. In turn the profit-maximising firm strategically increase its production. An opposite effect comes from consumer surplus. The idea that CSR firms account for consumer surplus is very closely related to the literature on strategic delegation and sales targets for managers in oligopolies (Vickers, 1985 and Fershtman and Judd, 1987). Essentially, firms have incentives to commit to put a greater weight on output in an oligopoly so as to induce rivals to reduce their output. In the light of this literature, the reason for why profits can be higher for a CSR firm is that committing to being a CSR firm can be one way of strategically committing to higher output.

Of course, capital accumulation in steady state depends on the levels of output. Comparing the levels of capital accumulated in steady state yields:

$$
k_{1}^{s s}-k_{2}^{s s}=\frac{2 \gamma m(\eta+\rho)-3 b \mu}{(3-\gamma)(A-\delta)(\eta+\rho)}>0,
$$

for

$$
m>\widetilde{m} \equiv \frac{3 b \mu}{2 \gamma(\eta+\rho)} .
$$

From Proposition 2 we can derive and confront the steady state profits. Plugging $q_{1}^{s s}$ and $x_{1}^{s s}$ into $\pi_{1}$ and $q_{2}^{s s}$ into $\pi_{2}$ and comparing $\pi_{1}$ and $\pi_{2}$ yields:

$$
\begin{gathered}
\pi_{1}-\pi_{2}= \\
\frac{4 b(5 \gamma-3) \mu z m(\eta+\rho)+8(1-\gamma) \gamma z m^{2}(\eta+\rho)^{2}-b^{2}\left[(3-\gamma)^{2} v^{2}+12 \mu^{2} z\right]}{4(3-\gamma)^{2} z(\eta+\rho)^{2}}>0
\end{gathered}
$$

for

$$
m>\widehat{m} \equiv \frac{b(3-5 \gamma) \mu z(\eta+\rho)+\sqrt{b^{2}(\gamma-3)^{2} z(\eta+\rho)^{2}\left(\mu^{2} z-2(\gamma-1) \gamma v^{2}\right)}}{4(1-\gamma) \gamma z(\eta+\rho)^{2}}
$$

Finally, note that

$$
\begin{gathered}
\widehat{m}-\widetilde{m}= \\
\frac{b(3-\gamma)\left[\mu z-\sqrt{z\left(\mu^{2} z+2(1-\gamma) \gamma v^{2}\right)}\right]}{4(1-\gamma) \gamma z(\eta+\rho)}>0,
\end{gathered}
$$

for $\mu, z, v>0, \gamma \in[0,1]$. The ongoing discussion can be summarised as follows

Proposition 3. For (i) $m>\widehat{m}$, the CSR firm accumulates more capital and obtains higher profits than its profit-maximising competitor.

(ii) $\widehat{m}>m>\widetilde{m}$, the CSR firm accumulates more capital and obtains lower profits than its profit-maximising competitor.

(iii) $\widetilde{m}>m$, the CSR firm accumulates less capital and obtains lower profits than its profit-maximising competitor.

Proposition 3 shows that market size plays an important role in determining the level of 
profits and capital accumulation according to the type of firm. A CSR performs better in the presence of large markets. The intuition behind this result is the following. The presence of consumer surplus in the CSR objective function increases the output compared to its competitor, while taking into account pollution has an opposite effect. The first effect more than offset the second effect for large markets, due to consumer surplus being a quadratic function of output. This in turn affects profits and capital accumulation.

\section{Stability of equilibrium}

In order to discuss the dynamic structure of the game, we are going to show its state-costate dynamic system. (7) implies

$$
x_{1}^{*}(t)=-\frac{\nu}{2 z} \lambda_{12}^{*}(t)=-\frac{\nu\left[\left[(\rho+\eta) \lambda_{12}(0)+b\right] e^{(\rho+\eta) t}-b\right]}{2(\rho+\eta) z},
$$

whereas the expressions for $q_{1}^{*}(t)$ and $q_{2}^{*}(t)$ involving the costate variables can be derived from (6) and (8), in particular: ${ }^{4}$

$$
\begin{gathered}
q_{1}^{*}(t)=\frac{1}{\gamma-3}\left[-m(\gamma+1)+2 \lambda_{11}^{*}(t)-2 \mu \lambda_{12}^{*}(t)+(\gamma-1) \lambda_{21}^{*}(t)-\mu(\gamma-1) \lambda_{22}^{*}(t)\right], \\
q_{2}^{*}(t)=\frac{1}{\gamma-3}\left[m(\gamma-1)-\lambda_{11}^{*}(t)+\mu \lambda_{12}^{*}(t)-(\gamma-2)\left(\lambda_{21}^{*}(t)-\mu \lambda_{22}^{*}(t)\right] .\right.
\end{gathered}
$$

By plugging (17), (18) and (19) into the kinematic equations (1) for $i=1,2$, and (2) and setting $\lambda_{22}^{*}(t) \equiv 0$, we achieve the 6 ODE state-costate dynamic system:

$$
\left\{\begin{array}{l}
\dot{k}_{1}^{*}(t)=(A-\delta) k_{1}^{*}(t)-\frac{1}{\gamma-3}\left[-m(\gamma+1)+2 \lambda_{11}^{*}(t)-2 \mu \lambda_{12}^{*}(t)+(\gamma-1) \lambda_{21}^{*}(t)\right] \\
\dot{k}_{2}^{*}=(A-\delta) k_{2}^{*}(t)-\frac{1}{\gamma-3}\left[m(\gamma-1)-\lambda_{11}^{*}(t)+\mu \lambda_{12}^{*}(t)-(\gamma-2) \lambda_{21}^{*}(t)\right] \\
\dot{S}^{*}(t)=-\eta S(t)+\frac{\mu}{\gamma-3}\left[-2 m+\lambda_{11}^{*}(t)+\lambda_{21}^{*}(t)\right]+\left[\frac{\nu^{2}}{2 z}-\frac{\mu^{2}}{\gamma-3}\right] \lambda_{12}^{*}(t) \\
\dot{\lambda}_{11}^{*}(t)=(\rho+\delta-A) \lambda_{11}^{*}(t) \\
\dot{\lambda}_{12}^{*}(t)=(\rho+\eta) \lambda_{12}^{*}(t)+b \\
\dot{\lambda}_{21}^{*}(t)=(\rho+\delta-A) \lambda_{21}^{*}(t)
\end{array}\right.
$$

The following propositions show the optimal productive capacities and the optimal pollu-

\footnotetext{
${ }^{4}$ We are going to omit most calculations to lighten the discussion. All calculations are available from the authors upon request.
} 
tion stock, respectively, alongside with the related conditions under which the transversality conditions hold.

Proposition 4. If $A>\max \left\{\rho+\eta+\delta, \frac{\rho+2 \delta}{2}\right\}$ and the following relations are satisfied:

$$
\begin{aligned}
& \frac{m(\gamma+1)+2 \mu b}{A-\delta}+\frac{2 \lambda_{11}(0)+(\gamma-1) \lambda_{21}(0)}{\rho+2 \delta-2 A}-\frac{2 \mu\left[(\rho+\eta) \lambda_{12}(0)+b\right]}{(\rho+\eta)(\rho+\eta-A+\delta)}=0, \\
& -\frac{m(\gamma-1)+\mu b}{A-\delta}-\frac{\lambda_{11}(0)+(\gamma-2) \lambda_{21}(0)}{\rho+2 \delta-2 A}+\frac{\mu\left[(\rho+\eta) \lambda_{12}(0)+b\right]}{(\rho+\eta)(\rho+\eta-A+\delta)}=0,
\end{aligned}
$$

then the transversality conditions (10) hold when the optimal costates $\lambda_{11}^{*}(t), \lambda_{12}^{*}(t)$ and $\lambda_{21}^{*}(t)$ are not identically zero and the optimal productive capacities are given by:

$$
\begin{aligned}
& k_{1}(t)=\frac{1}{\gamma-3}\left[\frac{m(\gamma+1)+2 \mu b}{\delta-A}-\frac{2 \lambda_{11}(0)+(\gamma-1) \lambda_{21}(0)}{\rho+2 \delta-2 A} e^{(\rho+\delta-A) t}+\frac{2 \mu\left[(\rho+\eta) \lambda_{12}(0)+b\right]}{(\rho+\eta)(\rho+\eta-A+\delta)} e^{(\rho+\eta) t}\right]+ \\
& +\left[k_{1}(0)+\frac{1}{\gamma-3}\left(\frac{m(\gamma+1)}{A-\delta}+\frac{2 \lambda_{11}(0)+(\gamma-1) \lambda_{21}(0)}{\rho+2 \delta-2 A}-\frac{2 \mu\left[(\rho+\eta) \lambda_{12}(0)+b\right]}{(\rho+\eta)(\rho+\eta-A+\delta)}+\frac{2 \mu b}{A-\delta}\right)\right] e^{(A-\delta) t}, \\
& k_{2}(t)=\frac{1}{\gamma-3}\left[\frac{m(\gamma-1)+\mu b}{\delta-A}+\frac{\lambda_{11}(0)+(\gamma-2) \lambda_{21}(0)}{\rho+2 \delta-2 A} e^{(\rho+\delta-A) t}-\frac{\mu\left[(\rho+\eta) \lambda_{12}(0)+b\right]}{(\rho+\eta)(\rho+\eta-A+\delta)} e^{(\rho+\eta) t}\right]+ \\
& +\left[k_{2}(0)+\frac{1}{\gamma-3}\left(-\frac{m(\gamma-1)}{A-\delta}-\frac{\lambda_{11}(0)+(\gamma-2) \lambda_{21}(0)}{\rho+2 \delta-2 A}+\frac{\mu\left[(\rho+\eta) \lambda_{12}(0)+b\right]}{(\rho+\eta)(\rho+\eta-A+\delta)}-\frac{\mu b}{A-\delta}\right)\right] e^{(A-\delta) t},
\end{aligned}
$$

Proof. See Appendix.

Proposition 5. The optimal pollution stock is given by:

$$
\begin{gathered}
S^{*}(t)=\frac{-2 m \mu}{\eta(\gamma-3)}-b\left[\frac{\nu^{2}}{2 z}-\frac{\mu^{2}}{\gamma-3}\right] \frac{(\rho+\eta) \lambda_{12}(0)+b}{\eta(\rho+\eta)}+\left[\frac{\nu^{2}}{2 z}-\frac{\mu^{2}}{\gamma-3}\right] \frac{\left[(\rho+\eta) \lambda_{12}(0)+b\right] e^{(\rho+\eta) t}}{(\rho+2 \eta)(\rho+\eta)}+ \\
+\frac{\mu\left(\lambda_{11}(0)+\lambda_{21}(0)\right) e^{(\rho+\delta-A) t}}{(\gamma-3)(\rho+\delta+\eta-A)}+\left[S(0)-\left[\frac{\nu^{2}}{2 z}-\frac{\mu^{2}}{\gamma-3}\right] \frac{\left[(\rho+\eta) \lambda_{12}(0)+b\right]}{(\rho+2 \eta)(\rho+\eta)}+\right. \\
\left.\quad+\frac{2 m \mu}{\eta(\gamma-3)}-\frac{\mu\left(\lambda_{11}(0)+\lambda_{21}(0)\right)}{\gamma-3}-\frac{b}{\eta(\rho+\eta)}\left[\frac{\nu^{2}}{2 z}-\frac{\mu^{2}}{\gamma-3}\right]\right] e^{-\eta t}
\end{gathered}
$$

hence the related transversality condition is verified if $\delta<A$ and if the shadow price $\lambda_{12}^{*}(t)$ is constant, i.e. $\lambda_{12}^{*}(t)=-\frac{b}{\rho+\delta}$.

Proof. See Appendix.

Note that condition $\delta<A$ also holds under the assumptions of Proposition 3. The above results clarify the characteristics of the shadow prices of the stock of pollution from the standpoint of the industrial strategies: the profit-maximizing firm attaches no price to the pollution dynamics, whereas the CSR firm attributes a negative constant shadow price to it. Such outcome is standard in differential games involving a pollution stock: by construction, if the 
externality enters the payoff functions with a negative effect, its shadow price turns out to be negative.

Because the costate variable $\lambda_{12}^{*}(t)$ is constant at equilibrium by Proposition 4 , we can reduce the dynamic system by one equation and obtain a 6-ODE dynamic system, whose Jacobian matrix of does not need to be evaluated at any steady state because all involved equations are linear:

$$
J=\left[\begin{array}{ccccc}
A-\delta & 0 & 0 & a_{1} & a_{2} \\
0 & A-\delta & 0 & b_{1} & b_{2} \\
0 & 0 & -\eta & c_{1} & c_{2} \\
0 & 0 & 0 & \rho+\delta-A & 0 \\
0 & 0 & 0 & 0 & \rho+\delta-A
\end{array}\right],
$$

where $a_{j}, b_{j}, j=1,2$, are the constant coefficients contained in (20), in particular $a_{1}=-\frac{2}{\gamma-3}$, $a_{2}=-\frac{\gamma-1}{\gamma-3}, b_{1}=\frac{1}{\gamma-3}, b_{2}=\frac{\gamma-2}{\gamma-3}, c_{1}=\frac{\mu}{\gamma-3}, c_{2}=\frac{\mu}{\gamma-3}$. Such Jacobian matrix is upper triangular, hence it is particularly simple to determine its eigenvalues The spectrum of $J$ turns out to be $\sigma(J)=\{A-\delta,-\eta, \rho+\delta-A\}$, where $-\eta$ is a negative eigenvalue having algebraic multiplicity $1, \rho+\delta-A$ is negative too, having multiplicity 2 , and the positive eigenvalue $A-\delta$ has algebraic multiplicity 2 , resulting in a 3-dimension stable manifold and a 2-dimension unstable manifold.

\section{Concluding remarks}

We have investigated a state-linear differential game describing an asymmetric, duopoly with quantity competition, capacity accumulation à la Ramsey and polluting production. Compared to some recent contribution on the analysis of CSR in a dynamic setting, focussing on the dynamic of CSR effort (Wirl et al., 2013), in this paper we have examined the evolution of capital accumulation in the comparison between a CSR and a profit-maximising firm. We find that, with a sufficiently large market, the CSR firm makes higher profits than its profit-seeking firm, and accumulates more capital. For medium-size markets, the CSR firm earns more profits but accumulates less capital than the competitor. In small markets, the profit-maximising firm earns more and accumulates more capital.

Although our analysis does not dwell upon a mixed oligopoly setting, some similarities between a public and a CSR firm may emerge, since we defined a CSR firm's objective function as a share of social welfare, loosely speaking. After the seminal paper due to Merrill and Schneider (1966), the literature on mixed oligopoly started developing only in the eighties. ${ }^{5}$

\footnotetext{
${ }^{5}$ See De Fraja and Delbono (1990) for a survey.
} 
De Fraja and Delbono (1989) showed that, if a public firm may wish to maximise industry welfare, its pursuit of this objective in interaction with private profit maximising firm will lead to obtain a greater profit than that obtained by its otherwise identical private competitors. Cremer et al. (1989) suggest that to nationalise a single existing firm can be socially optimal if there are no other public firms in the industry, in some cases, nationalising the whole industry might be best, although unrealistic. De Fraja (1991) shows that the presence of a public firm in an oligopoly may improve the overall efficiency of the industry. This occurs as the low prices set by the public producer forces the private firms to cut their costs to match their prices. This effect is obtained even if the public firm has a certain grade of inefficiency compared to the private firm. Most recently, Matsumura and Matsushima (2004) elaborate this latest approach by endogenising production costs through cost-reducing activities. They show that the private firm cost becomes lower than the public firm cost because the former engages in excessive strategic cost-reducing activities.

All these contributions are however developed in a static setting. Conversely, the literature on dynamic mixed oligopoly is scarce. In a recent paper, Casadesus-Masanell and Ghemawat (2006) analyse a dynamic mixed duopoly in which a profit-maximizing competitor interacts with a competitor that prices at marginal cost, with the cumulation of output affecting their relative positions over time. Their idea is to model the interactions between Linux, an open source operating system, and Microsoft's Windows and consequently emphasizes demand-side learning effects that generate dynamic scale economies. Our setting may indeed be extended by considering different cost technologies among competitors as a further factor of asymmetry. 


\section{References}

[1] Alves, C. and Santos-Pinto, L. 2008. A Theory of Corporate Social Responsibility in Oligopolistic Markets. Cahiers de Recherches Economiques du Departement d'Economerie et d'Economie politique (DEEP) 09.04, Université de Lausanne, Faculté des HEC, DEEP.

[2] Arora, S. and Gangopadhyay, S. 1995. Toward a Theoretical Model of Voluntary Overcompliance. Journal of Economic Behavior and Organization 28: 289-309.

[3] Baron, D. 2001. Private Politics, Corporate Social Responsibility, and Integrated Strategy. Journal of Economics and Management Strategy 10: 7-45.

[4] Baron, D.P. and Diermeier, D. (ed.). 2007. Special Issue on Nonmarket Strategy and Social Responsibility. Journal of Economics and Management Strategy, 16, Issue 3.

[5] Baron, D.P. 2009. A Positive Theory of Moral Management, Social Pressure, and Corporate Social Performance. Journal of Economics and Management Strategy, 18: 7-43.

[6] Becchetti, L. and Ciciretti, R. 2009. Corporate Social Responsibility and Stock Market Performance. Applied Financial Economics, 19, 1283-1293.

[7] Becchetti, L. and Solferino, N. 2005. The dynamics of ethical product differentiation and the habit formation of socially responsible consumers. Working Paper.

[8] Benabou, R. and Tirole, J. 2010. Individual and Corporate Social Responsibility. Economica 77: 1-19.

[9] Besley, T. and Ghatak, M. 2010. Retailing Public Goods: The Economics of Corporate Social Responsibility. Journal of Public Economics 91: 1645-1663.

[10] Brekke, K. A. and Nyborg, K. 2008. Attracting Responsible employees: Green Production as Labor Market Screening. Resource and Energy Economics 30: 509-526.

[11] Casadesus-Masanell, R. and Ghemawat, P. 2006. Dynamic Mixed Duopoly: A Model Motivated by Linux vs. Windows. Management Science 52: 1072-1084.

[12] Cellini, R. and Lambertini, L. 1998. A Dynamic Model of Differentiated Oligopoly with Capital Accumulation. Journal of Economic Theory 83: 145-155.

[13] Cellini, R., Lambertini, L. and Leitmann, G. 2005. Degenerate Feedback and Time Consistency in Differential Games. In Hofer, E.P. and Reithmeier, E. (eds), Modeling and Control of Autonomous Decision Support Based Systems. Proceedings of the 13th International Workshop on Dynamics and Control. Aachen, Shaker Verlag.

[14] Chatterji, A.K., Levine, D. I. and Toffel, M.W. 2009. How Well Do Social Ratings Actually Measure Corporate Social Responsibility? Journal of Economics and Management Strategy, 18: 125-169. 
[15] Cremer, H., Marchand, M., Thisse, J.F. 1989. The Public Firm as an Instrument for Regulating an Oligopolistic Market. Oxford Economic Papers 41: 283-301.

[16] D'Aspremont, C., Jacquemin, A., Gabszewicz, J. J. and Weymark, J. A. 1983. On the Stability of Collusive Price Leadership. The Canadian Journal of Economics 16: 17-25.

[17] De Fraja, G. and Delbono, F. 1989. Alternative Strategies of a Public Enterprise in Oligopoly. Oxford Economic Papers 41: 302-311.

[18] De Fraja, G. and Delbono, F. 1990. Game Theoretic Models of Mixed Oligopoly. Journal of Economic Surveys 4: 1-17.

[19] De Fraja, G., 1991. Efficiency and Privatisation in Imperfectly Competitive Industries. Journal of Industrial Economics 39: 311-321.

[20] Dockner, E.J, Jørgensen, S., Long, N.V. and Sorger, G. 2000. Differential Games in Economics and Management Science. Cambridge, Cambridge University Press.

[21] Donsimoni, M. P., Economides, N. S. and Polemarchakis, H. M. 1986. Stable Cartels. International Economic Review 27: 317-327.

[22] Fernández-Kranz D. and Santaló, J. 2010. When Necessity Becomes a Virtue: The Effect of Product Market Competition on Corporate Social Responsibility. Journal of Economics and Management Strategy, 19: 453-487.

[23] Fershtman, C. and Judd, K.L. 1987. Equilibrium Incentives in Oligopoly. American Economic Review 77: 927-940.

[24] Fershtman, C. and Muller, E. 1984. Capital accumulation games of infinite duration, Journal of Economic Theory 33: 322-339.

[25] Fisher-Vanden, K. and Thorburn, K.S. 2011. Voluntary Corporate Environmental Initiatives and Shareholder Wealth. Journal of Environmental Economics and Management, 62, 430-445.

[26] Friedman M. 1962. Capitalism and Freedom. University of Chicago Press.

[27] Friedman M. 1970. The Social Responsibility of Business is to Increase its Profits. New York Times Magazine 13: 122-126.

[28] Garcia-Gallego, A. and Georgantzís, N. 2009. Market Effects of Changes in Consumers' Social Responsibility. Journal of Economics and Management Strategy, 19: 453-487.

[29] Kamien, M. I. and Schwartz, N. 1979. Optimal capital accumulation and durable good production, Z. National Ökonomie 37: 25-43.

[30] Kopel, M. and Brand, B. 2012. Socially responsible firms and endogenous choice of strategic incentives. Economic Modelling 29: 982-989. 
[31] Kotchen, M. J. 2006. Green Markets and Private Provision of Public Goods. Journal of Political Economy 114: 816-845.

[32] Lambertini, L. and Tampieri, A. 2010. Corporate social responsibility in a mixed oligopoly. Department of Economics, University of Bologna, Working Paper $\mathbf{7 2 3}$.

[33] Lambertini, L. and Tampieri, A. 2012. Corporate social responsibility and firms ability to collude. In S. Boubaker and D.K. Nguyen (eds), Board Directors and Corporate Social Responsibility, Houndmills, Palgrave Macmillan.

[34] Manasakis, C., Mitrokostas, E. and Petrakis, E. .2007. Corporate Social Responsibility in Oligopolistic Markets. Working Paper University of Crete.

[35] Margolis, J. D., H. A. Elfenbein and Walsh, J. P. 2009. Does it Pay to Be Good...And Does it Matter? A Meta-Analysis of the Relationship between Corporate Social and Financial Performance. http://dx.doi.org/10.2139/ssrn.1866371.

[36] Mehlmann, A. 1988. Applied Differential Games. New York, Plenum Press.

[37] Merrill, W. and Schneider, N. 1966. Government Firms in Oligopoly Industries: A ShortRun Analysis. Quarterly Journal of Economcs 80: 400-412.

[38] Mohr, L.A., Webb, D.J. and Harris, K.E. 2001. Do Consumers Expect Companies to Be Socially Responsible? The Impact of Corporate Social Responsibility on Buying Behavior. Journal of Consumer Affairs 35: 45-72.

[39] Murray, K. and Volgel, C. 1997. Using a Hierarchy of Effects Approach to Gauge the Effectiveness of Corporate Social Responsability to Generate Goodwill Toward the Firm: Financial versus Nonfinancial Impacts. Journal of Business Research 38: 141-159.

[40] Reinganum, J. 1982. A dynamic game of R\&D: Patent protection and competitive behavior, Econometrica 50: 671-688.

[41] Vickers, J. 1985. Delegation and the Theory of the Firm. Economic Journal 95: 138-147.

[42] Wirl, F., Feichtinger, G., and Kort, P.M. 2013. Individual firm and market dynamics of CSR activities. Journal of Economic Behavior and Organization 86: 169-182. 


\section{Appendix}

\section{Proof of Proposition 1}

The coordinate $x_{1}^{s s}$ is positive irrespective of all parameter values. If $\gamma<1, q_{2}^{s s}$ is positive. If we assume that $A>\delta, k_{2}^{s s}$ is positive too. The condition

$$
m>\frac{2 \mu b}{(\gamma+1)(\rho+\eta)}
$$

ensures the feasibility of $q_{1}^{s s}$ and $k_{1}^{s s}$, whereas

$$
m>\frac{b\left[(3-\gamma) \nu^{2}+2 \mu^{2} z\right]}{4 z \mu(\rho+\eta)}
$$

ensures the feasibility of $S^{s s}$.

\section{Proof of Proposition 4}

Plugging the optimal costates into the 2 kinematic equations of $k_{1}^{*}(t)$ and $k_{2}^{*}(t)$ and solving them yields the solutions (23) and (24). Consequently, substituting them in the transversality conditions (10) leads to the following limits:

$$
\begin{gathered}
\lim _{t \longrightarrow+\infty} \lambda_{11}(0)\left\{\frac { 1 } { \gamma - 3 } \left[\frac{m(\gamma+1)+2 \mu b}{\delta-A} e^{(\delta-A) t}-\frac{2 \lambda_{11}(0)+(\gamma-1) \lambda_{21}(0)}{\rho+2 \delta-2 A} e^{(\rho+2 \delta-2 A) t}+\right.\right. \\
\left.+\frac{2 \mu\left[(\rho+\eta) \lambda_{12}(0)+b\right]}{(\rho+\eta)(\rho+\eta-A+\delta)} e^{(\rho+\eta+\delta-A) t}\right]+k_{1}(0)+ \\
\left.+\frac{1}{\gamma-3}\left(\frac{m(\gamma+1)}{A-\delta}+\frac{2 \lambda_{11}(0)+(\gamma-1) \lambda_{21}(0)}{\rho+2 \delta-2 A}-\frac{2 \mu\left[(\rho+\eta) \lambda_{12}(0)+b\right]}{(\rho+\eta)(\rho+\eta-A+\delta)}+\frac{2 \mu b}{A-\delta}\right)\right\}=0 \\
\quad \lim _{t \longrightarrow+\infty} \lambda_{21}(0)\left\{\frac { 1 } { \gamma - 3 } \left[\frac{m(\gamma-1)+\mu b}{\delta-A} e^{(\delta-A) t}+\frac{\lambda_{11}(0)+(\gamma-2) \lambda_{21}(0)}{\rho+2 \delta-2 A} e^{(\rho+2 \delta-2 A) t}\right.\right. \\
\left.\quad-\frac{\mu\left[(\rho+\eta) \lambda_{12}(0)+b\right]}{(\rho+\eta)(\rho+\eta-A+\delta)} e^{(\rho+\eta+\delta-A) t}\right]+k_{2}(0)+ \\
\left.+\frac{1}{\gamma-3}\left(-\frac{m(\gamma-1)}{A-\delta}-\frac{\lambda_{11}(0)+(\gamma-2) \lambda_{21}(0)}{\rho+2 \delta-2 A}+\frac{\mu\left[(\rho+\eta) \lambda_{12}(0)+b\right]}{(\rho+\eta)(\rho+\eta-A+\delta)}-\frac{\mu b}{A-\delta}\right)\right\}=0
\end{gathered}
$$

which hold for all $\lambda_{11}(0)$ and $\lambda_{21}(0)$ when $A$ satisfies the condition $A>\max \left\{\eta+\delta, \frac{\rho+2 \delta}{2}\right\}$ and when identities (21) and (22) are verified.

\section{Proof of Proposition 5}

By plugging the optimal costates $\lambda_{11}^{*}(t), \lambda_{12}^{*}(t), \lambda_{21}^{*}(t)$ into the dynamics of pollution, we can calculate (25). When replacing such expression in the transversality condition involving $S^{*}(t)$, some contributions of the product are exponential functions with positive exponents, hence 
we can only consider a constant shadow price of pollution to ensure that the transversality condition holds. In particular, if $\lambda_{12}^{*}(t)=-b /(\rho+\eta)$ for all $t \in[0,+\infty)$, it boils down to:

$$
\begin{gathered}
\lim _{t \longrightarrow+\infty}\left[-\frac{b}{\rho+\eta}\right] \cdot\left[\frac{-2 m \mu}{\eta(\gamma-3)} e^{-\rho t}+\frac{\mu\left(\lambda_{11}(0)+\lambda_{21}(0)\right) e^{(\delta-A) t}}{(\gamma-3)(\rho+\eta+\delta-A)}+\left(S(0)+\frac{2 m \mu}{\eta(\gamma-3)}\right.\right. \\
\left.\left.-\frac{\mu\left(\lambda_{11}(0)+\lambda_{21}(0)\right)}{\gamma-3}-\frac{b}{\eta(\rho+\eta)}\left(\frac{\nu^{2}}{2 z}-\frac{\mu^{2}}{\gamma-3}\right)\right) e^{-(\rho+\eta) t}\right],
\end{gathered}
$$

which vanishes if $\delta<A$. 


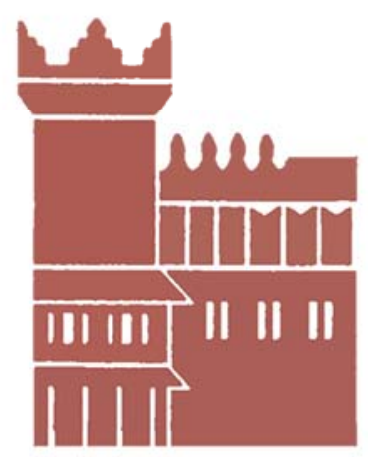

Alma Mater Studiorum - Università di Bologna DEPARTMENT OF ECONOMICS

Strada Maggiore 45

40125 Bologna - Italy

Tel. +39051 2092604

Fax +390512092664

http://www.dse.unibo.it 